\title{
Analysis of Conduction Intervals in Normal Electrophysiological Studies: Establishment of Reference Values the Brazilian Population
}

\author{
Tiago Luiz Luz Leiria, ${ }^{\circledR}$ Catarine Benta Lopes dos Santos, ${ }^{\circledR}$ Roberto Tofani Sant'anna, ${ }^{\circledR}$ Julia Santana Trombetta, \\ Gabriela Osterkamp, ${ }^{\circledR}$ Marcelo Lapa Kruse, ${ }^{\circledR}$ Leonardo Martins Pires, ${ }^{\circledR}$ Gustavo Glotz Lima ${ }^{\circledR}$ \\ Instituto de Cardiologia / Fundação Universitária de Cardiologia (IC/FUC), Porto Alegre, RS - Brazil
}

\section{Abstract}

Background: In the investigation of cardiac rhythm disorders, a normal electrophysiological (EPS) study is associated with a favorable prognosis. One of the normality criteria is established by conduction intervals within expected range.

Objective: To establish reference values in EPS for the intracavitary conduction intervals (PA, AH and HV) in a Brazilian population.

Methods: A retrospective cohort study of the first 1,500 patients submitted to EPS ablation was performed at Instituto de Cardiologia do Rio Grande do Sul, Brazil. The EPS was considered normal if the test was performed for diagnostic purpose; absence of induced arrhythmias; and conduction intervals within the expected range. The REDCap software was used for data collection and management, and the SPSS Statistics 22.0 used for data analysis. Continuous variables were compared with Student's t-test for independent samples and categorical variables with the chi-square test $\left(\mathrm{X}^{2}\right)$. Values of $\mathrm{p} \leq 0.05$ were considered significant.

Results: A total of 124 (8.3\%) with EPS considered normal were included; mean age was $52 \pm 21$ years, and 63 were male. The mean values in milliseconds of PA, AH and HV were $23 \pm 9,88 \pm 25$ and $44 \pm 7$, respectively. The PA, $\mathrm{AH}$, and HV percentile ranges were $13-25,81-107$ and $40-52$, respectively. When the patients were divided into three age groups ( 1 to 18 years, 19 to 64 years and 65 or more), we observed that the group of older patients had significantly higher values of PA, AH and HV compared with younger patients.

Conclusion: This study showed that intracavitary conduction intervals in a sample of the Brazilian population were similar to previously published studies. Elderly patients tend to have higher values of intracavitary conduction intervals in EPS. Future studies including broader age ranges could enable the acquisition of more reliable and reproducible reference values. (Int J Cardiovasc Sci. 2020; 33(5):488-494)

Keywords: Electrocardiography/methods; Arrhythmias, Cardiac; Syncope/physiopathology; Syncope/therapy; Predictive Value of Tests; Treatment Outcome; Brazil/epidemiology.

\section{Introduction}

Electrophysiological study (EPS) is a useful test in the evaluation of the cardiac conduction system. ${ }^{1,2}$ Moreover, it has an additional role in investigating symptoms such as palpitations, lipothymia and syncope, especially in established structural heart disease or when electrocardiogram (ECG) shows abnormalities that suggest an arrhythmic cause for these symptoms. ${ }^{3}$

Mailing Address: Tiago Luiz Luz Leiria

Avenida Princesa Isabel, n.395. Postal Code: 90620-000, Porto Alegre, RS - Brazil. E-mail: pesquisa.leiria@gmail.com
A normal EPS is characterized by the following: no triggering of sustained arrhythmias (with clinical repercussion), no evidence of accessory pathway or ectopic focus, and sinus and nodal functions presenting expected normal responses as defined by the literature. In certain situations, patients with a normal EPS have a better prognosis regarding mortality. ${ }^{4}$ Thus, knowledge

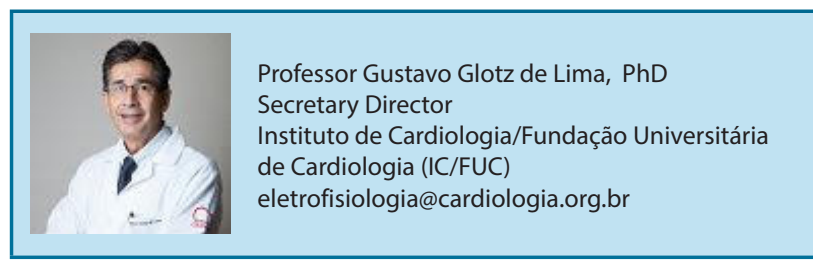

Manuscript received on December 11, 2018; reviewed on September 16, 2019; accepted on November 03, 2019. 
of the normal, or reference intervals is fundamental to the interpretation of EPS results for each patient. Normal intervals should be established from a healthy population and address pathological implications of values out of these ranges. ${ }^{5}$ The PA interval evaluates the conduction time of depolarization in the right atrium, from the sinus node to the atrioventricular (AV) node. The AH interval determines the conduction time within the compact AV node to the His bundle. The His-ventricular (HV) interval estimates the conduction time through the His-Purkinje system.

Several studies on cardiac electrophysiology have sought to establish a consensus of values of electrical stimulation conduction that would be associated with a higher risk of adverse events. ${ }^{6,7}$ However, these values have not been established from systematic sampling yet, and the reference values commonly used were those obtained in studies published in the 60's and 70's. ${ }^{8}$ No studies including diverse populations have been conducted and so far, no study has been performed in Brazil.

The aim of the present study was to establish the pattern of normal intracavitary values by EPS in the Brazilian population.

\section{Methods}

\section{Patient selection}

A historical cohort study of the first 1,500 patients undergoing EPS and / or ablation was performed at the Electrophysiology Service of the Institute of Cardiology of Rio Grande do Sul - ICFUC. The study included patients undergoing EPS from June 1997 to October 2010. The data used in this study were obtained from the reports of the electrophysiology laboratory and the hospital medical records.

\section{Electrophysiological study}

The EPS included: measurement of sinus node recovery time; measurement of intracavitary intervals (PA, AH, $\mathrm{HV})$; assessment of the induction of supraventricular and ventricular arrhythmias by programmed stimulation; identification of accessory pathway; and determination of atrial, ventricular and AV node refractory periods. The tests were performed as previously described. ${ }^{9,10}$

The EPS was considered abnormal in any of the following situations: sinus bradycardia and abnormal sinus node recovery time, ${ }^{1,2} \mathrm{HV}$ interval $\geq 70 \mathrm{~ms}$ or atrioventricular block (second- or third degree) during atrial pacing; ${ }^{3}$ induction of sustained ventricular tachycardia or ventricular fibrillation; ${ }^{4}$ induction of any type of supraventricular tachycardia that caused hypotension or symptoms; ${ }^{5}$ presence of accessory pathway. This normality pattern used in our study was based on previous studies in the literature. ${ }^{11}$ Besides that, all patients underwent a drug withdrawal protocol prior to the EPS; those with dromo- or chronotropic effects were discontinued for a period of five half-lives prior to the study. Patients with abnormal EPS were excluded from the study.

The PA interval was defined as the interval from the onset of the $\mathrm{P}$ wave to the first atrial deflection recorded on the HIS bundle ECG; ${ }^{2} \mathrm{HA}$, measured at the HISbundle ECG, was defined as the interval from the first rapid atrial deflection to the beginning of HIS deflection; and $\mathrm{HV}$ interval of the HIS bundle, measured from the onset of ventricular depolarization by ECG or local ECG, whichever was earlier.

To record signals and pacing maneuvers, multipolar catheters were placed within the upper right atrium, His bundle region and right ventricular tip. All data were digitally recorded using Prucka - Cardiolab system (GE Prucka; GE Healthcare, Waukesha, WI) with a $30 \mathrm{~Hz}$ $500 \mathrm{~Hz}$ pass filter. The few traces not digitally available were measured again from the printed reports, by the same electrophysiologist.

Our study population was divided into three age groups, following the World Health Organization age groups definition ${ }^{12}-1-18$ years, 19-64 years and 65 and over. The purpose of this division was to assess the potential effect of age on driving intervals and how this could influence the establishment of normal values.

\section{Statistical analysis}

Data were stored in a dedicated database designed with the help of the RedCap platform (Research Electronic Data Capture - hosted at the University Foundation of Cardiology - RS). Tables of absolute frequencies and percentages for characterization of general sample were prepared. Data were exported to Excel 2010 software (Microsoft Excel. Redmond, Washington: Microsoft, 2010. Computer Software) and then analyzed using the SPSS 22.0 software (IBM Corp. Released 2013. IBM SPSS Statistics for Windows, Version 22.0. Armonk, NY: IBM Corp.). Continuous variables with normal distribution were expressed as mean and standard deviation and 
those with non-normal distribution as median and interquartile range. Variables with normal distribution were compared using the Student's t-test for independent samples, and data with non-Gaussian distribution were analyzed with the nonparametric Kruskal-Wallis test. Categorical variables were expressed as percentages and compared with the chi-square test $\left(X^{2}\right)$ with subsequent Bonferroni correction.

In all comparisons, we considered a critical alpha of $\leq 0.05$ and a beta error of 0.8 . Values with $p \leq 0.05$ were considered significant.

\section{Results}

We evaluated the first 1,500 patients from 7,090 cases in our service. Of these, 124 had EPS considered normal, that is, no changes in the conduction system or evidence of sinus node dysfunction (Figure 1). From the cases initially considered normal, three were excluded from analysis due to lack of clinical or demographic data. In the analysis of the pattern of normal intracavitary values - PA, AH, HV -, we identified those patients whose test results within the expected range. Outlying HV values were reviewed by one experienced electrophysiologist and then another four patients, with significant conduction disturbance and / or $\mathrm{HV}>70 \mathrm{~ms}$, were excluded.

Characteristics of the individuals included in the study are summarized in Table 1.

\section{Intracavitary interval values and distribution}

The mean values of PA, AH and HV were, respectively, $23 \pm 9 \mathrm{~ms}, 97 \pm 34 \mathrm{~ms}$ and $45 \pm 8 \mathrm{~ms}$. The $25^{\text {th }}$ and $75^{\text {th }}$ percentile range for $\mathrm{PA}, \mathrm{AH}$, and $\mathrm{HV}$ was 18 to 26,76 to 114 , and 40 to 52 , respectively (Table 2 ). Distribution curves of the ranges are shown in Figure 2.

In the analysis of conduction intervals by age group, the group of patients older than 65 years showed significantly higher values of all intervals when compared to the youngest group (PA, $\mathrm{p}=0.048$; $\mathrm{AH}$, $\mathrm{p}=0.004 ; \mathrm{HV}, \mathrm{p}=0.001)$. The youngest group also had shorter HV intervals when compared to the intermediate
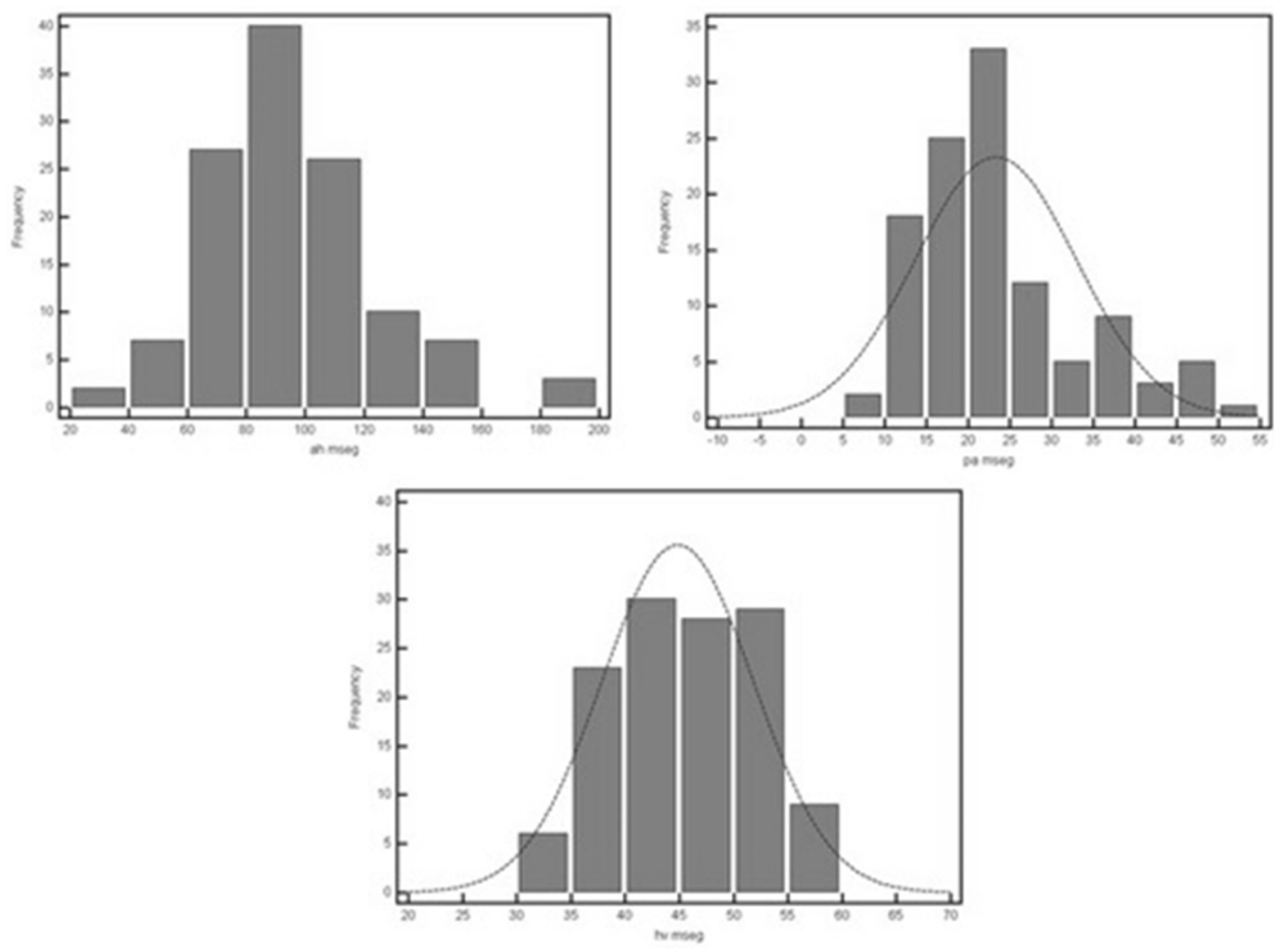

Figure 1 - Protocol and patients included for analysis. 
Table 1 - Clinical and demographic characteristics of the 124 patients included in the study

\begin{tabular}{lcc} 
& $\mathbf{n}=\mathbf{1 2 4}$ & (\%) \\
\hline Male sex & 63 & 50.8 \\
Average age in years & $52 \pm 21$ & \\
EPS indication & & \\
Pathway system rating & 85 & 0.8 \\
Syncope & 15 & 12.1 \\
Evaluate sinus function & 10 & 8 \\
Supraventricular tachycardia Hx & 2 & 1.6 \\
Hx PCR & 2 & 1.6 \\
Pre-excitation on ECG & 2 & 1.6 \\
Vertigo & 1 & 0.8 \\
Palpitations & 1 & 0.8 \\
Atrial flutter Hx & 1 & 0.8 \\
Hx of ventricular tachycardia & 1 & 0.8 \\
Other & 4 & 4 \\
\hline $\begin{array}{l}\text { EPS: electrophysiological study; Hx: previous history; CRP: } \\
\text { cardiopulmonary arrest; ECG: electrocardiogram. }\end{array}$ \\
\hline
\end{tabular}

age group $(\mathrm{p}=0.008)$. Table 4 shows the comparison of conduction intervals between the age groups.

\section{Discussion}

The normal patterns of intracavitary values used by the ICFUC electrophysiology service are based on international parameters, which were described and compiled between the 1960s and 1980s (Table 3)..$^{10,13-18}$

\begin{tabular}{|c|c|c|c|c|}
\hline \multicolumn{5}{|c|}{$\begin{array}{l}\text { Table } 2 \text { - Intracavitary conduction interval by } \\
\text { percentiles }\end{array}$} \\
\hline Normal & Average & P 25 & P 50 & P 75 \\
\hline PA & $23( \pm 9)$ & 18 & 21 & 26 \\
\hline $\mathrm{AH}$ & $97( \pm 34)$ & 76 & 91 & 114 \\
\hline HV & $45( \pm 8)$ & 40 & 46 & 52 \\
\hline \multicolumn{5}{|c|}{$\begin{array}{l}P A \text { interval defined as the interval from the onset of the P wave to the } \\
\text { first atrial deflection recorded on the HIS bundle electrocardiogram; } \\
\text { the AH interval determined the conduction time within the compact } \\
A V \text { node to the His bundle; the HV interval of the HIS bundle was } \\
\text { measured from the onset of ventricular depolarization by ECG or } \\
\text { local EC. }\end{array}$} \\
\hline
\end{tabular}

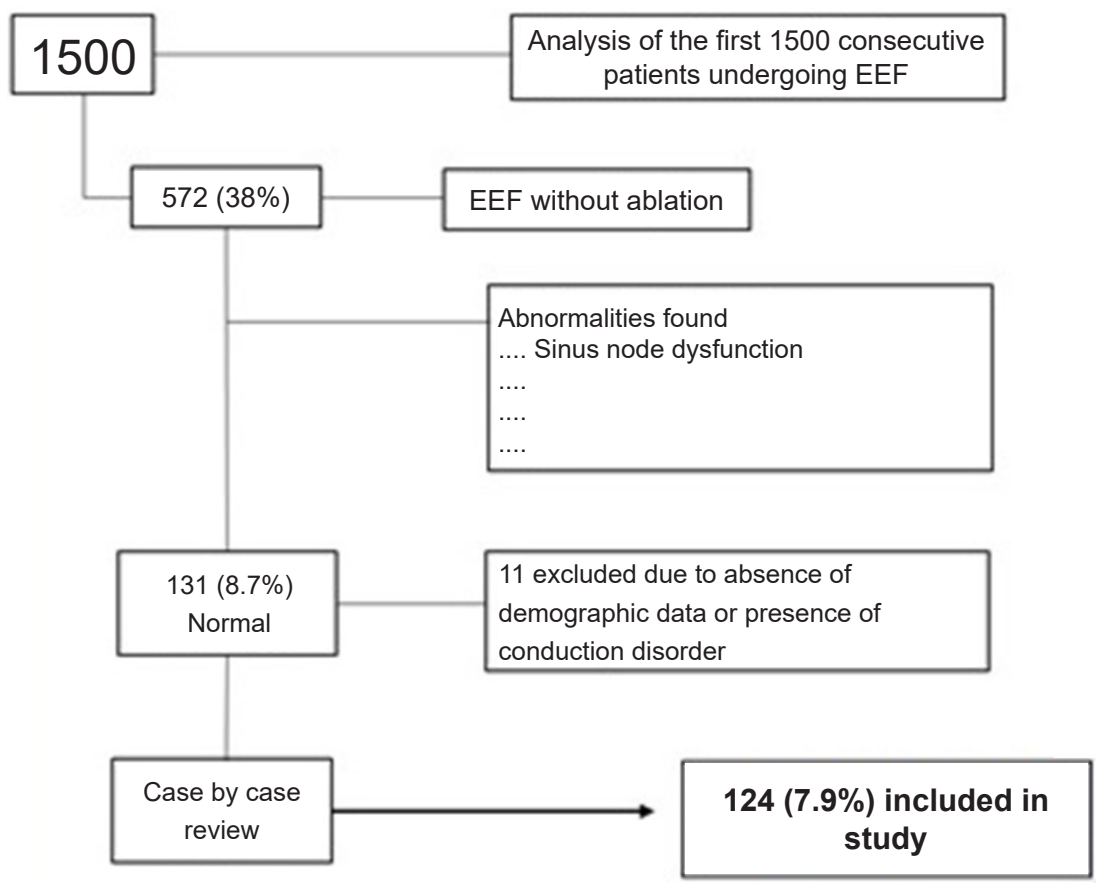

Figure 2 - PA, AH and HV interval distribution according to frequency. 
These studies have limitations, since intracavitary values were obtained not only from healthy patients but also from patients with some type of AV block or infraHisian block. Therefore, it is important to analyze the results with caution, not only to establish the patterns of our own population, but also to reevaluate the pattern of normality, considering that the studies were conducted decades ago.

The prevalence of cardiovascular diseases increases with age..$^{10}$ The cardiac conduction system is affected by the increase in elastic and collagenous tissues

Table 3 - Intracavitary conduction intervals according to different studies; data compiled by Josephson et al. ${ }^{10}$ and updated by the authors

\begin{tabular}{lccc}
\hline Laboratory & PA & AH & HV \\
\hline Narula & $25-60$ & $50-120$ & $35-45$ \\
Damato & $24-45$ & $60-140$ & $30-55$ \\
Castellanos & $20-50$ & $50-120$ & $25-55$ \\
Schulenburg & $85-150$ & $35-55$ & - \\
Peuch & $30-55$ & $45-100$ & $35-55$ \\
Beckeit & $10-50$ & $50-125$ & $35-45$ \\
Rosen & $9-45$ & $54-130$ & $31-55$ \\
Josephson & $9-45$ & $54-130$ & $31-55$ \\
IC -FUC & $18-26$ & $76-114$ & $40-50$ \\
\hline
\end{tabular}

$P A$ interval defined as the interval from the onset of the $P$ wave to the first atrial deflection recorded on the HIS bundle electrocardiogram; the AH interval determined the conduction time within the compact $A V$ node to the His bundle; the HV interval of the HIS bundle was measured from the onset of ventricular depolarization by ECG or local EC. associated with aging. There is more than $90 \%$ reduction in the number of cells with automatism by the age of 75 years. Age-associated calcification may affect the conduction system and increase the prevalence of atrioventricular block. ${ }^{11}$ The PR interval, a marker of atrioventricular conduction, increases from $159 \mathrm{~ms}$ (on average) at 20-35 years of age to $172 \mathrm{~ms}$ at 60 years of age. ${ }^{12}$ We believe that the differences in $\mathrm{AH}$ and in $\mathrm{HV}$ intervals between age groups observed in our study reflect these changes (Figure 3).

Clinically, changes in conduction intervals should be interpreted in the context of the symptoms. ${ }^{13}$ Shorter $\mathrm{PA}$ and $\mathrm{AH}$ ranges could reflect increased adrenergic tone or supranormal conduction. Shorter HV intervals generally represent the presence of accessory pathway. HV values are useful in the evaluation of patients with syncope and have a moderate accuracy to predict future occurrence of total atrioventricular block when the values exceed $70 \mathrm{~ms}^{14}$

The present study has some limitations. First, the study made a retrospective analysis of a prospectively collected data, and thus did not have a uniform methodology or adequate review; second, it presented data from a single center, with a single team, which increases the reliability of the measurements, but decreases the external validity of the results; third, the study did not evaluate the presence of comorbidities and the use or not of drugs; also, it did not present a multivariate analysis of possible independent factors that could influence interval values. Finally, all patients included had an indication for electrophysiological study with or without ablation regardless of participation in the research, that is, they did not necessarily represent a healthy population. This may have influenced the values considered "normal".

Table 4 - Comparison of conduction intervals between different age groups

\begin{tabular}{|c|c|c|c|c|c|c|}
\hline \multirow{2}{*}{ Range (ms) } & \multicolumn{3}{|c|}{ Age group } & \multicolumn{3}{|c|}{ Difference ( $p$ value) } \\
\hline & $\begin{array}{c}1 \text { to } 18 \text { years } \\
n=10\end{array}$ & $\begin{array}{c}19 \text { to } 64 \text { years } \\
n=75\end{array}$ & $\begin{array}{c}>64 \text { anos } \\
n=75\end{array}$ & 1 and 2 & 1 and 3 & 2 and 3 \\
\hline PA & $19( \pm 6)$ & $22( \pm 9)$ & $27.5( \pm 11)$ & 0.640 & 0.048 & 0.009 \\
\hline $\mathrm{AH}$ & $94( \pm 19)$ & $88( \pm 25.5)$ & $106( \pm 30)$ & 0.398 & 0.004 & 0.403 \\
\hline $\mathrm{HV}$ & $38( \pm 6)$ & $44( \pm 7)$ & $47( \pm 6)$ & 0.008 & 0.001 & 0.107 \\
\hline
\end{tabular}

PA interval defined as the interval from the onset of the $p$ wave to the first atrial deflection recorded on the HIS bundle electrocardiogram; the AH interval determined the conduction time within the compact $A V$ node to the His bundle; the HV interval of the HIS bundle was measured from the onset of ventricular depolarization by ECG or local ECG. ${ }^{*} p$ values were obtained by the Kruskal-Wallis test. 


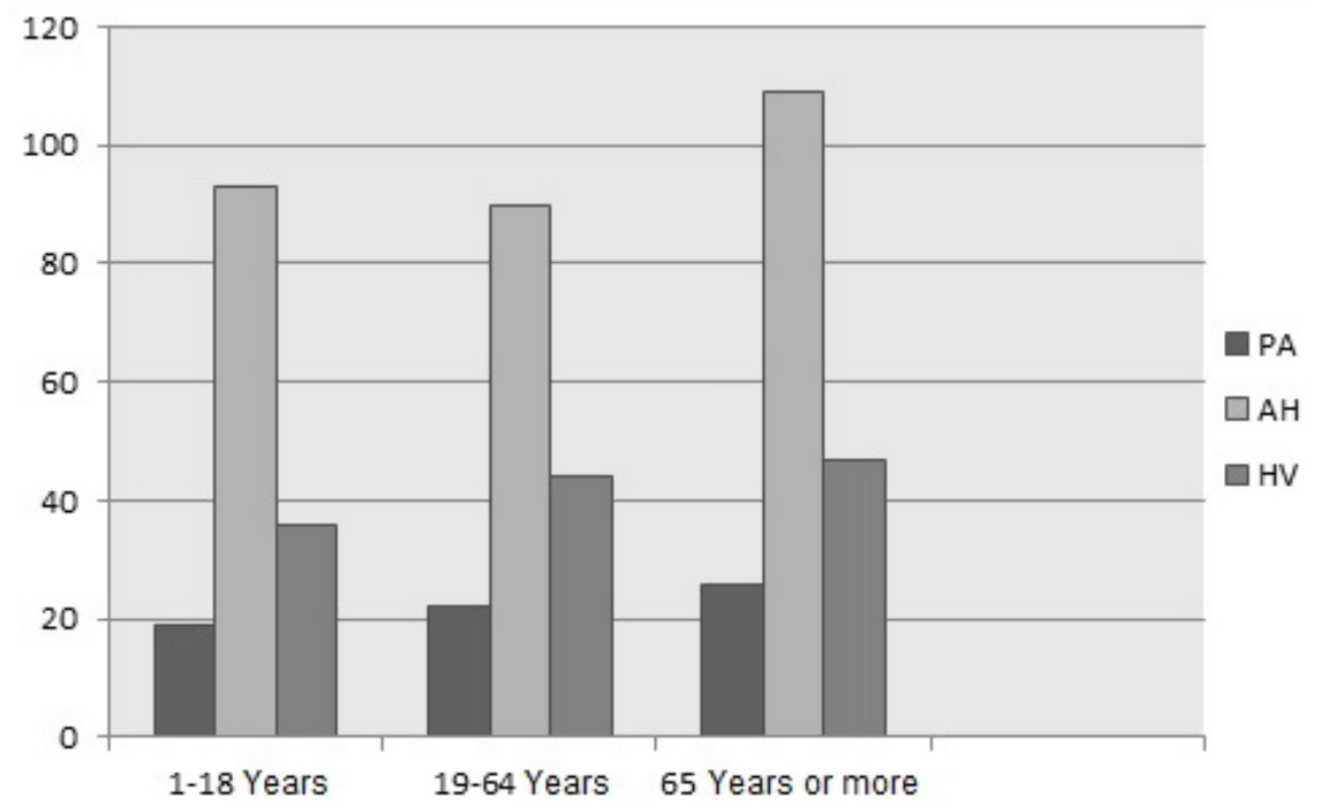

Figure 3 - Intracavitary intervals according to age group (ms).

\section{Conclusion}

This study showed that intracavitary conduction intervals in a sample of the Brazilian population were similar to previously published studies. Elderly patients tend to have higher values of intracavitary conduction intervals in EPS. However, it was not possible to infer from this study whether there is an association between the number of existing comorbidities and the increase in conduction intervals. Future studies including broader age ranges could enable the acquisition of more reliable and reproducible reference values.

\section{Author contributions}

Conception and design of the research: Leiria TLL, Lima GG. Acquisition of data: Santos CBL, Trombetta JS, Osterkamp G. Analysis and interpretation of the data: Leiria TLL, Trombetta JS, Lima GG. Statistical analysis: Leiria TLL, Sant'anna RT. Writing of the manuscript: Leiria TLL, Santos CBL, Pires LM, Lima GG. Critical revision of the manuscript for intellectual content: Sant'anna RT, Kruse ML.

\section{Potential Conflict of Interest}

No potential conflict of interest relevant to this article was reported.

\section{Sources of Funding}

There were no external funding sources for this study.

\section{Study Association}

This study is not associated with any thesis or dissertation work.

\section{Ethics approval and consent to participate}

This study was approved by the Ethics Committee of the Instituto de Cardiologia / Fundação Universitária de Cardiologia (IC/FUC) under the protocol number 5256/16. All the procedures in this study were in accordance with the 1975 Helsinki Declaration, updated in 2013. Informed consent was obtained from all participants included in the study. 


\section{References}

1. Shen WK, Sheldon RS, Benditt DG, Cohen MI, Forman DE, Goldberger ZD, et al. 2017 ACC/AHA/HRS guideline for the evaluation and management of patients with syncope: A report of the American College of Cardiology/American Heart Association Task Force on Clinical Practice Guidelines and the Heart Rhythm Society. Heart Rhythm. 2017;14(8):e155-217.

2. Bachinsky WB, Linzer M, Weld L, Estes NA 3rd. Usefulness of clinical characteristics in predicting the outcome of electrophysiologic studies in unexplained syncope. Am J Cardiol. 1992;69(12):1044-9.

3. Aslam R, Girerd N, Brembilla-Perrot B. What is The Utility of Electrophysiological Study in Elderly Patients with Syncope and Heart Disease? Indian Pacing Electrophysiol J. 2015;15(1):32-42.

4. Kushner JA, Kou WH, Kadish AH, Morady F. Natural history of patients with unexplained syncope and a nondiagnostic electrophysiologic study. J Am Coll Cardiol. 1989;14(2):391-6.

5. Katayev A, Balciza C, Seccombe DW. Establishing reference intervals for clinical laboratory test results: is there a better way? Am J Clin Pathol. 2010;133(2):180-6.

6. Scheinman MM, Peters RW, Modin G, Brennan M, Mies C, O'Young J. Prognostic value of infranodal conduction time in patients with chronic bundle branch block. Circulation. 1977;56(2):240-4.

7. Nazari N, Keykhavani A, Sayah S, Hekmat M, Golabchi A, Rad MA, et al. Role of electrophysiological study in patients with syncope and bundle branch block. J Res Med Sci. 2014;19(10):961-4.

8. Strait JB, Lakatta EG. Aging-associated cardiovascular changes and their relationship to heart failure. Heart Fail Clin. 2012;8(1):143-64.
9. Simão MF, Rios MN, Leiria TL, Kruse ML, Pires LM1, SantAnna RT, et al. Electrophysiological studies and radiofrequency ablations in children and adolescents with arrhythmia. Arq Bras Cardiol. 2015;104(1):53-7.

10. Josephson ME. Josephson's Clinical Cardiac Electrophysiology. Philadelphia:Wolters Kluwer Health; 2015.

11. Brignole M, Menozzi C, Moya A, Garcia-Civera R, Mont L, Alvarez M, et al. Mechanism of syncope in patients with bundle branch block and negative electrophysiological test. Circulation. 2001;104(17):2045-50.

12. World Health Organization. (WHO). World report on ageing and health. Geneva: WHO Library Cataloguing-in-Publication Data; 2015.

13. Narula OS, Scherlag BJ, Samet P, Javier RP. Atrioventricular block. Localization and classification by His bundle recordings. Am J Med. 1971;50(2):146-65.

14. Damato AN, Lau SH, Helfant R, Stein E, Patton RD, Scherlag BJ, et al. A study of heart block in man using His bundle recordings. Circulation. 1969;39(3):297-305.

15. Damato AN, Lau SH. Clinical value of the electrogram of the conduction system. Prog Cardiovasc Dis. 1970;13(2):119-40.

16. Schuilenburg RM, Durrer D. Conduction disturbances located within the His bundle. Circulation. 1972;45(3):612-28.

17. Bekheit S, Murtagh JG, Morton P, et al. Studies of heart block with His bundle electrograms. Br Heart J. 1972;34(7):717-34.

18. Rosen KM. Evaluation of cardiac conduction in the cardiac catheterization laboratory. Am J Cardiol. 1972;30(6):701-3. 